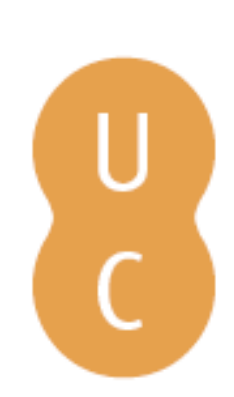

\title{
pompalina
}

\section{Acompanhamento social, capacitação e responsabilização: a "subjetivação" da intervenção social?}
Autor(es):
Albuquerque, Cristina Pinto
Publicado por: Imprensa da Universidade de Coimbra
URL
persistente:
URI:http://hdl.handle.net/10316.2/29875
DOI:
DOI:http://dx.doi.org/10.14195/978-989-26-0769-6_2
Accessed : $\quad$ 26-Apr-2023 16:06:30

A navegação consulta e descarregamento dos títulos inseridos nas Bibliotecas Digitais UC Digitalis, UC Pombalina e UC Impactum, pressupõem a aceitação plena e sem reservas dos Termos e Condições de Uso destas Bibliotecas Digitais, disponíveis em https://digitalis.uc.pt/pt-pt/termos.

Conforme exposto nos referidos Termos e Condições de Uso, o descarregamento de títulos de acesso restrito requer uma licença válida de autorização devendo o utilizador aceder ao(s) documento(s) a partir de um endereço de IP da instituição detentora da supramencionada licença.

Ao utilizador é apenas permitido o descarregamento para uso pessoal, pelo que o emprego do(s) título(s) descarregado(s) para outro fim, designadamente comercial, carece de autorização do respetivo autor ou editor da obra.

Na medida em que todas as obras da UC Digitalis se encontram protegidas pelo Código do Direito de Autor e Direitos Conexos e demais legislação aplicável, toda a cópia, parcial ou total, deste documento, nos casos em que é legalmente admitida, deverá conter ou fazer-se acompanhar por este aviso.

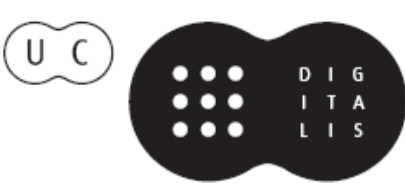




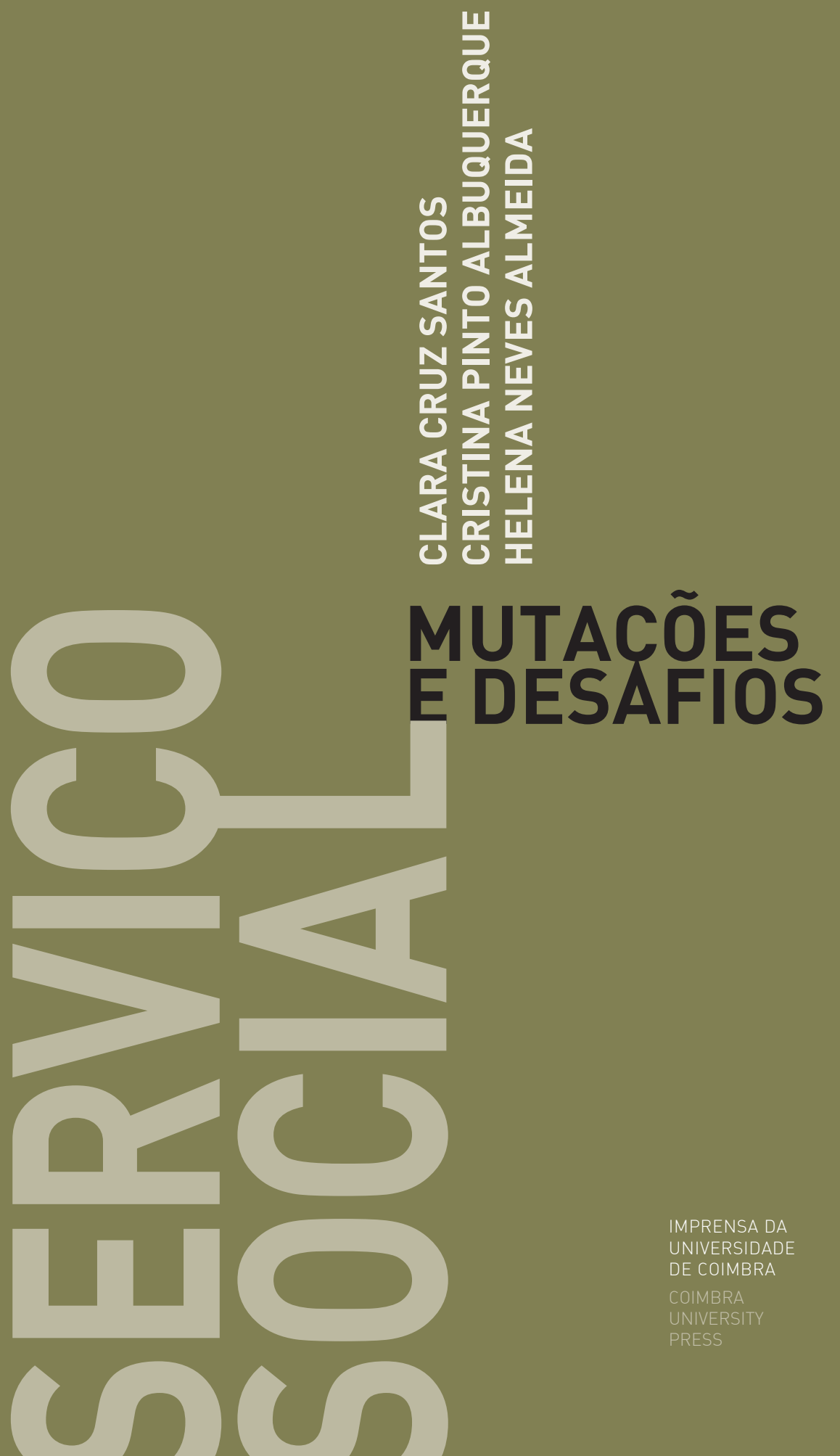


Cristina Pinto Albuquerque

\section{CAPI'TULO II}

\section{ACOMPANHAMENTO SOCIAL, CAPACITAÇÃo \\ E RESPONSABILIZAÇÃO. A “SUBJETIVAÇÃO” \\ DA INTERVENÇÃO SOCIAL?}

\section{Introdução}

A revalorização do papel da sociedade civil, dos cidadãos e do mercado, numa lógica de produção mista de bem-estar social, tem-se constituído, sobretudo nas últimas duas décadas, como o eixo estruturante das reformas em curso nos modelos sociais europeus, e em particular no contexto português.

Com efeito, a um modelo de Estado omnipresente, suspeito de gerar dependências perversas e comprovamente ineficaz na superação das causas de problemas estruturais, como a pobreza ou o desemprego, parece suceder hoje um Estado "animador" (Donzelot \& Estèbe, 1994) ou implicacionista, que coloca o enfoque na necessidade de participação dos diversos agentes, sociais, económicos e políticos, na conceção e implementação de respostas mais adequadas à complexidade dos problemas atuais e às necessidades e expectativas dos cidadãos, mas também potenciadoras de uma gestão mais eficiente e eficaz de recursos escassos e diferenciados. O Estado deixa assim de constituir-se como agente único de proteção, articulando-se doravante com outros agentes na produção corresponsável de bem-estar socioeconómico e de coesão social assente em pressupostos de justiça e de direitos de participação, de reconhecimento, de inserção e de utilidade. 
A "nova geração" de políticas sociais traduz estes pressupostos, neutralizando uma lógica de homogeneização dos problemas e de tipificação de públicos e respostas, em prol de uma valorização da singularidade e da equidade. Assim, as (novas) políticas sociais estruturam-se em torno de uma lógica de territorialização (aproveitando maiêuticamente as potencialidades e especificidades dos territórios locais), de inserção e ativação (enfatizando primordialmente a implicação ativa dos cidadãos, particularmente dos que se encontram em dificuldade, na reconstrução de percursos de vida e associando a efetivação de deveres, devidamente contratualizados, à prestação de um direito), e finalmente, de singularização (adequando as respostas aos perfis de problemas e de sujeitos, considerando as respetivas potencialidades, constrangimentos e expectativas, pessoais e sociais).

As políticas de inserção, nomeadamente, ainda que de uma forma por vezes imprecisa e fluida, procuram responder aos novos desafios, dando coerência e objetividade a um novo espaço de inteligibilidade e perceção do social. Na verdade, constituem-se como um terreno privilegiado para concretização do paradigma político da implicação, procurando responder aos "novos territórios da questão social" (Le-Strat, 1996) e às novas prioridades e contornos da ação pública neste domínio.

Os dispositivos de inserção, considerados por Pierre Rosanvallon (1995) essencialmente como um conjunto de práticas sociais experimentais de combate à exclusão, não em função da generalidade e da identidade categorial mas em função do caráter doravante singular dos acontecimentos, inscreve-se num esforço de racionalização do social, revitalizando a assunção ética da responsabilidade dos indivíduos na construção do progresso pessoal e social. Tais políticas fundamentam e fundamentam-se, assim, em novos pressupostos de intervenção, distanciando-se das políticas universais integrativas, mas também não se confundindo com ações particularistas de cariz paliativo ou compensatório. Podem por isso considerar-se como novos "direitos da idade democrática” (Rosanvallon, 1995), articulando as ajudas e a participação / implicação dos ajudados na construção do Social.

Ora, tais orientações não deixam de se constituir como impulsionadoras de mudanças na forma de refletir, de conceber e de legitimar a intervenção social contemporânea. A lógica da "subjetivação" (no sentido de priorização 
do sujeito), em concreto, sobre a qual incidirá primordialmente a nossa reflexão, assenta e decorre de princípios e processos de trabalho que valorizam, em primeira linha, os percursos pessoais.

Com efeito, como procuraremos argumentar, esta orientação subjetivante ${ }^{2}$, introduzida na atual retórica política e na prática social, não deixa de colocar questões pertinentes e inéditas, nomeadamente, no que diz respeito aos processos de avaliação e de acompanhamento dos sujeitos; sujeitos estes que se constituem, nesta perspetiva, como os recursos fundamentais em processos de construção e de (re)condução de si próprios.

As orientações normativas, e as práticas delas decorrentes, parecem centrar-se pois doravante particularmente num trabalho de autoprodução e de autoapropriação de vivências e de trajetórias pessoais, sociais e profissionais, por parte de cada sujeito, sob mediação, mais ou menos explícita e contínua, de interventores sociais diversos (assistentes sociais, psicólogos, conselheiros, coachers, educadores, entre outros).

Este trabalho, se por um lado permite suplantar ou minimizar alguns dos efeitos de passividade e de desresponsabilização dos sujeitos potenciados pelas políticas sociais tradicionais compensatórias, não deixa, por outro lado, de abrir a possibilidade (que deve ser devidamente refletida) de enviesamentos "neo-paternalistas" (Castel, 1995) e moralistas. Na verdade, como evidenciam Cantelli e Genard (2007), enquanto as práticas paternalistas tradicionais, de contornos moralizantes e dominadores, se baseavam em referências institucionais e normativas consistentes e relativamente consensuais, como o trabalho, a família, a nação, entre outras, o paternalismo atual assenta, pelo contrário, como sublinha Castel (1995), em dinâmicas de sobreresponsabilização dos indivíduos na reconstrução ou preservação da

\footnotetext{
${ }^{2}$ Como salienta Jean-Louis Genard (2007) trata-se de uma orientação que não se restringe à esfera da política social, mas que emerge igualmente, por exemplo, no domínio da neo-gestão de recursos humanos (onde adquire relevância a noção de empowerment, de responsabilização e de competência), no domínio das práticas terapêuticas (psicológicas, assistenciais ou farmacológicas), no domínio da pedagogia, ao atribuir-se ao professor o papel crucial de promotor das potencialidades e competências dos estudantes. Para mais desenvolvimentos sobre os diferentes domínios nos quais uma tal orientação se evidencia consultar os diversos contributos do número 46 da revista Droit et Société - Action Publique et Subjectivité, coordenada por Fabrizio Cantelli e Jean-Louis Genard (2007).
} 
sua identidade e experiências, sem o correspondente acesso a referências partilhadas e, como tal, orientadoras e reconhecíveis como legítimas.

Estas considerações e o conjunto de implicações sociopolíticas e éticas que as mesmas comportam, particularmente relevantes no universo da intervenção social que desde sempre se encontrou fustigado pela suspeita de controlo social, não podem porém ser dissociadas de uma reflexão sobre os quadros normativos e sociológicos subjacentes. Na verdade, uma constatação de fundo a este propósito é a de que o sujeito atual, incerto, vulnerável, mas também reflexivo, se encontra sem "bússolas" credíveis e submetido a uma tensão irredutível entre autonomia e heteronomia; autonomia entendida destarte como poder / dever de conduzir a sua existência, pessoal e social, em contextos instáveis e plurinormativos (Genard, 2007).

Neste contexto, a intervenção social tem hoje um importante papel a cumprir na reconstrução de elos, desde logo entre os sujeitos e as suas próprias experiências e aprendizagens, mas também não deixa de estar sujeita a um conjunto de transformações nas suas finalidades e processos de trabalho, particularmente em termos de acompanhamento, que se constituem como o mote da reflexão a desenvolver. Assim, discutiremos, num primeiro momento, as implicações associadas à "subjetivação" da ação sociopolítica, para, num segundo momento, refletir em torno das (novas) lógicas e modalidades de intervenção social que, nesse quadro, tendem a emergir.

\section{Do redimensionamento da ação sociopolítica ...}

Na senda das reflexões de autores como Foucault (1966), Elias (1973) ou Gauchet (1985), é atualmente incontornável, política e epistemologicamente, a problematização do conjunto de reconfigurações da ação pública ancorada em pressupostos subjetivantes. Os contornos incitativos, motivacionais e autonómicos que subjazem às finalidades de inúmeras orientações políticas e dispositivos contemporâneos, sobretudo no domínio social, remetem-nos para a consideração da singularidade, que havia sido, sobretudo no pós-Guerra (1945), progressivamente elidida da gramática e das práticas do Estado por via do movimento igualitário. 
Hoje a produção complexa de pluri-inseguranças e a emergência do circunstancial e da precariedade, como marcas substantivas das atuais "sociedades de riscos" (Beck, 1992) globalizados, tendem a colocar em causa as teorias basilares e as respostas institucionais, que serviram de esteio à vivência e à confiança modernas. Com efeito, as atuais situações atípicas e as novas formas de insegurança e incerteza que emergem não são enquadráveis, ou explicáveis, por referência a categorias, conceitos ou discursos normativos tradicionais ${ }^{3}$.

A ação pública contemporânea, outrora alicerçada em valores e princípios pelo menos potencialmente absolutos e consensualizados, passa assim, consequente e progressivamente, a nortear-se por objetivos assentes numa lógica de contingência e de adaptabilidade, tanto mais evidente quanto os contextos de crise socioeconómica se aprofundam e a incapacidade de resposta cabal às procuras e problemas crescentes se evidencia. Esta evidência tende mesmo a originar ou potenciar processos renovados de ação e de análise do real, acompanhados de novas formas de institucionalização social e política, potencialmente ignidoras e catalizadoras de movimentos, ora de inovação, ora de retração, de sedimentação, ou de defesa, mais ou menos corporativa, do adquirido.

Deste modo, a intervenção social e política já não parece norteada pela preocupação de domínio do futuro (cada vez mais difícil de perspetivar e de controlar), mas antes, pela tentativa de manter visíveis, existentes, num espaço-tempo fluido e incerto, todos aqueles cujos laços sociais, económicos e políticos se encontram fragilizados, ou rasgados.

Assim sendo, transformam-se os critérios que permitem avaliar a consistência e permanência das existências individuais e coletivas, bem como os pressupostos do agir e da retórica inerente à conceção e avaliação das políticas públicas. A pluralidade de vivências, de valores, de trajetórias,

\footnotetext{
${ }^{3} \mathrm{Na}$ tentativa de apreender e categorizar as situações que escapam largamente à noção de risco, o Estado realiza, no dizer de N. Le Strat (1996, p. 91) uma espécie de «fuite en avant nosographique». Um exemplo desta obsessão classificatória diz respeito ao desemprego. À categoria "desempregado de longa duração", acrescenta-se rapidamente a categoria de "desempregado de muito longa duração", a que se segue a dos desempregados "com idades superiores a 50 anos" e assim por diante, numa tentativa, imparável e ilusória, de reduzir problemas complexos a classificações simples e passíveis de mensurabilidade.
} 
de universos de (não)sentido incategorizáveis, de processos excludentes, complexos e múltiplos, parecem de facto obrigar à passagem de uma racionalidade política e social ligada à gestão solidarista de riscos, para uma racionalidade "responsabilista" associada, por um lado, ao acompanhamento de situações específicas de dificuldade, de percursos concretos (de inserções e desinserções múltiplas) e de microacontecimentos, tendo como focalização imperativos de sobrevivência social e de construção ou apropriação de um espaço de visibilidade, num tecido social e económico cada vez mais fragmentado, e por outro, ao aproveitamento do risco como uma oportunidade. Nesta última lógica o risco já não se concebe como algo a exigir compensação ou reparação, mas antes, como suporte e impulso para atuar, para empreender. As políticas adquirem assim um cariz emancipatório, encorajando as pessoas a serem ativas e consagrando a atuação autónoma não só como uma necessidade, mas como um dever social (Soulet, 2007).

Esta forma de política, a que Giddens (1994) chama "generativa", já que se centra na geração de resultados pelo desenvolvimento autónomo das capacidades, assenta no pressuposto de que os indivíduos são capazes de identificar e de trabalhar o seu capital humano e social, superando as respetivas insuficiências, prevenindo comportamentos de risco (em termos de saúde, de investimentos económicos, etc) e identificando vias de desenvolvimento alternativas.

Ora, um tal pressuposto não se verifica para uma parte dos públicos com os quais os interventores sociais, e em particular os assistentes sociais, hoje trabalham, exigindo por isso finalidades e lógicas de intervenção e de acompanhamento distintas, sob pena de acentuar mecanismos excludentes e paradoxais associados, nomeadamente, à sobrevalorização de percursos e experiências adquiridas.

\subsection{Paradoxos associados à maximização do "mundo vivido"}

A mutação paradigmática que temos vindo a caracterizar coloca-nos, de facto, questões relevantes sobre a conceção de liberdade numa sociedade (pós) disciplinar e sobre o retorno (mais ou menos subtil) das teses associadas 
à individualização dos problemas sociais. Com efeito, as atuais ofensivas neoliberais e neoconservadoras, revitalizando os debates em torno da diferença e da legitimação das desigualdades, em nome de papéis naturais, estatutos prescritos ou mesmo "carências genéticas" das populações pobres e excluídas, bem como a valorização ortodoxa da meritocracia, obrigam a um questionamento sério em torno das conceções ideológicas e normativas da exclusão e da proteção social atual. Com efeito, neste contexto, pode reemergir o "velho" debate em torno do merecimento, ou imerecimento, da ajuda, em função de contrapartidas, por vezes simbólicas, destinadas ao "pagamento" da tolerância coletiva e à triagem entre os "bons" e os "maus" pobres.

A problematização de tais discursos afigura-se-nos como absolutamente fundamental para o redimensionamento do projeto democrático contemporâneo. Desde logo, é de sublinhar a ideia de que a análise focalizada da exclusão sobre os excluídos caricaturiza o social dualizando-o de forma maniqueísta. Neste sentido estar-se-ia a legitimar a própria exclusão como algo de residual, decorrente do funcionamento normal da sociedade que seleciona os melhores e que desvaloriza, no mesmo sentido, aqueles que fatalmente são mais fracos. Ora, se entendermos a exclusão como um processo que coloca em causa o todo social, um produto de contradições sociais, económicas e pessoais, inextrincavelmente ligadas, percebemos que integrados e não integrados fazem parte de um mesmo conjunto cuja unidade é problemática. Deste modo, agir verdadeiramente contra a exclusão implica a compreensão de que são as próprias regras do jogo social, político e económico e as suas racionalidades que necessitam de ser (re) interrogadas globalmente.

Nesta perspetiva, a coesão social só adquire substância mediante a consciência da presença e da existência concreta do Outro, no reconhecimento da "diferença fundadora" ${ }^{4}$ no cerne da vivência coletiva. O sentimento de pertença, numa rede social, comunicacional e simbólica, privilegiando mais o que unifica do que o que distancia, consubstancia-se como o princípio

\footnotetext{
4 Expressão utilizada por Begaud (1983). A "diferença fundadora”, associada à emergência da sociabilidade, reivindica-se e afirma-se não "por relação a..." (neste caso deveria falar-se, de acordo com a mesma autora de "diferença reflexo"), mas "em si" ou "por si".
} 
basilar de reconstituição do elo social, a que Simmel (1858-1918) chama "elo de reciprocidade", para designar o cruzamento de ações, situações e afetos.

De forma subjacente tem pois de evidenciar-se uma perspetiva concêntrica da sociedade, isto é, a consciência de que os diversos círculos só adquirem sentido, porque se encontram mutuamente ligados. À unidade, característica do projeto sociopolítico moderno, tem assim de suceder-se uma espécie de unicidade, traduzida no ajustamento de elementos plurais ${ }^{5}$ (Maffesoli, 1988).

A este propósito, Maffesoli (1988) refere-se ao tempo atual como o "tempo das tribos"; um tempo no qual se acentua a dimensão táctil da existência social. O ângulo de análise estético torna-se, nesta perspetiva, uma forma de reconhecimento mútuo. Refira-se que etimologicamente o conceito de estética é entendido como a faculdade comum de sentir, de experimentar, constituindo-se deste modo como a essência da atual religação dos indivíduos ao todo social ${ }^{6}$. Assim sendo, é a realidade da coexistência social, a potência afirmativa do conjunto que dá sentido à solidariedade e à reciprocidade, a que Maffesoli (1988) chama sociabilidade, constituindo-se, na sua ótica, como o "novo divino social".

Se assim é, os processos de invisibilização de existências, por um lado, ou de sobrevisualização de percursos (e dos respetivos falhanços), em sentido inverso, podem conduzir a dinâmicas profundas de sofrimento social, tanto mais acentuadas quanto cabe ao sujeito, de acordo com as novas prerrogativas de ação sociopolítica, reconstituir e provar a sua utilidade e visibilidade social.

\footnotetext{
${ }^{5}$ De acordo com a tese de Maffesoli (1988) existe uma "centralidade subterrânea informal" que assegura a permanência da vida em sociedade. Assiste-se, assim, ao retorno do "vitalismo" e à passagem de uma ordem essencialmente mecanicista para uma estrutura complexa, holística, de dominância orgânica e comunicacional. A "sociabilidade" traduz o relativismo de viver a grandeza e o trágico do quotidiano, a carga dos elementos mundanos, o todo exprimindo-se no nós. A sociabilidade corresponde, pois, à realidade da coexistência social e ao seu sentido intrínseco. Boulte (1995) considera, no entanto, redutor o modelo proposto por Maffesoli, já que reduz o estético ao sentir comum, o ético à ligação coletiva, a cultura ao costume e a convivialidade ao conteúdo de agrupamentos efémeros. "A appeler "réalisme» une telle vision limitée aux apparences, on en vient de fait à adopter une certaine forme de mépris de la vie, à nier les puissances de l'être et sa capacité à appréhender ce nouveau palier de complexité, auquel il est confronté par la marche de l'histoire” (Boulte, 1995, p. 34)

6 "Face à cette déliance polymorphe, naissent et croissent des aspirations de reliance, en particulier des aspirations de reliance sociale: les individus déliés, isolés, séparés, aspirent à être reliés, et à être reliés autrement. Ces aspirations émergentes constituent, me semble-t-il, un enjeu social crucial pour notre société, pour nos politiques sociales» (Bal, 1984, p. 49).
} 
Com efeito, a fragmentação dos referenciais estruturantes da identidade pessoal e social no passado, nomeadamente um estatuto profissional relativamente estável, produz hoje um número cada vez maior de sujeitos invisíveis, ou para utilizarmos o título da obra de Patrick Boulte (1995), de "indivíduos em pousio", não reconhecíveis no confronto com os outros. Como constata Elias (1991, cit. por Boulte, 1995, p. 90), hoje "o peso do "eu" substituiu o peso do "nós». Os excluídos não são mais aqueles que tentam escapar ao peso do "nós" (...), mas aqueles que não podem assegurar o peso do "eu»". Esta invisibilidade decorre assim sobretudo da inexistência de ocasiões ou condições sociais e políticas para fazer a "experiência de si"7 (Boulte, 1995), o que não significa colocar somente nos ombros do sujeito a construção e confirmação dessa experiência.

Não estabelecendo relações com o mundo, ou não tendo essa possibilidade efetiva, isolando-se de si mesmo e dos outros, num tempo indeterminado, entre um passado, que pode não se constituir como um marco existencial positivo, e um futuro sem consistência, o sujeito encontra-se excluído do mundo objetivo e dos referenciais e trocas concretas e simbólicas. O seu real não é visível, logo não possui legitimidade ${ }^{8}$. É pois a essência de uma vivência partilhada, das oportunidades para experimentar e experimentar-se no mundo, que se encontra inúmeras vezes inacessível às populações de excluídos.

Com efeito, a visibilidade das existências e das condutas, antes assegurada pela vigência de normas que permitiam grosso modo objetivar, quantificar e comparar as condutas, trajetórias e situações problema dos sujeitos, concretiza-se hoje de forma radicalmente distinta, como já salientámos. Destarte, fundamenta-se uma "tecnologia política dos indivíduos" (Le-Strat, 1996), destinada a assegurar a continuidade das presenças no contexto sociopolítico.

7 O desenvolvimento de meios para "fazer a experiência de si" deveria, na opinião de Boulte (1995), constituir-se mesmo como um critério para avaliar a eficácia das políticas públicas, nomeadamente, analisando, em cada ação, as formas e possibilidades de emergência de novos atores sociais.

8 Como afirma Hannah Arendt (1987) viver uma vida inteiramente privada é encontrar-se afastado de elementos essenciais para uma existência com verdadeira dimensão humana. É estar destituído da relação objetiva com os outros e partilhar com eles um mundo simbólico e material. É estar impossibilitado de atingir uma dimensão mais permanente que a própria vida. O homem privado não tem importância para os outros; aquilo que faz, aquilo que pensa, aquilo que sente não lhes interessa pois é como se não existisse. 
Como afirma Rancière (1995) a este propósito, a visibilidade das condutas passa, doravante, pelo "aclarar de si”, pela auto certificação daquilo que cada sujeito é, daquilo que faz ou não faz, das capacidades ou fragilidades que tem, em suma, um testemunho de verdade, ou de (auto e hetero) perceções, em relação a si mesmo.

Deste modo, cada indivíduo é intimado não apenas a restaurar a sua interioridade, aprendendo a revalorizar e utilizar as suas capacidades e experiências na reconstrução do seu lugar na sociedade, mas também, a visibilizar e a (com)provar, ou argumentar, publicamente esse trabalho de reconstrução de si, como justificação para a continuidade da sua inscrição como membro social e económico. Assim, ao contar a "sua história" o excluído adquire visibilidade no universo do outro. Um outro de cujo olhar necessita para Ser, para adquirir consistência existencial, como se falando evitasse o "desperdício de si" (Corbin, cit. por Astier, 1995).

O percurso de transformação de "um destino numa história" (Autès, 1992) pressupõe que o indivíduo em sofrimento social faça validar pelos outros as etapas desse percurso, demonstrando a coerência do seu discurso sob o ângulo da verdade (na medida em que deve ser conforme ao mundo objetivo), da justiça (pela comprovação de que conhece, compreende e pratica as regras sociais admissíveis) e da sinceridade (pela correspondência entre aquilo que diz e aquilo que verdadeiramente vivência, ou pode vir a vivenciar) (Boulte, 1995). A questão política central torna-se, pois, a concetualização de formas de utilizar e otimizar as "técnicas de si" (através das quais o indivíduo deve enunciar socialmente o que é e o que pretende e pode vir a ser), respeitando em simultâneo desvios, silêncios e fracassos, sem que tal permita a acusação e o julgamento de "mau caráter" ou de "pouco querer".

A compreensão da dimensão antropológica e simbólica da exclusão e da precariedade na atualidade permite-nos, por um lado, perceber que sem o suporte identitário de uma realidade objetiva à qual já não se pertence a única base de retorno ao real reside na interioridade, na experiência de si, no reencontro comunicacional com os outros, na reconstituição peça a peça de um projeto temporalmente consistente e, por outro, exige-nos o repensar dos critérios de pertença social, deslegitimando posicionamentos tolerantes que evidenciam o desprezo pela dignidade de alguns, pressuposto para a 
aniquilação da dignidade de todos. É preciso, como afirma Kouchner (1989), que se olhe os excluídos sem o olhar de reprovação que os obriga a apagar-se.

O papel de acompanhamento e de mediação social, tal como hoje é assegurado pelos interventores sociais, não deixa pois de se constituir como um recurso crucial na preservação desta inscrição das populações vulneráveis e excluídas no tecido social e económico e na criação das referidas oportunidades para "experimentar-se" no mundo. No entanto, o referido acompanhamento não pode esgotar-se num sucessão ininterrupta de momentos presentes, logo sem se fundamentar numa lógica estratégica de desenvolvimento e questionamento das desigualdades, cujas causas são necessariamente supraindividuais.

\section{2. ...ao redimensionamento da intervenção social}

Neste contexto, apesar de persistirem hoje práticas sociais e enquadramentos político-institucionais muito diferenciados parece-nos possível identificar duas novas tendências paralelas e, em muitos casos conflituantes, de agregação das diversas intervenções no domínio social: a) uma orientação gestionária, determinada por preocupações associadas à produção e avaliação de objetivos e resultados, tendo por base uma lógica de racionalização e de quantificação; e b) uma orientação subjetivante, que se concretiza em formas renovadas de acompanhamento social de sujeitos em situação de vulnerabilidade ou de exclusão.

Em consonância com esta última orientação, que em particular nos ocupa, saber trabalhar com os indivíduos competências sociais e de adaptabilidade a contextos em perpétua mudança, sobretudo face às condições de incerteza e de precarização que perpassam hoje as vivências individuais e coletivas, constitui-se como uma dimensão profissional fulcral no âmago da intervenção social contemporânea. Com efeito, os processos e técnicas de trabalho tradicionais revelam-se, no quadro da questão social contemporânea, por vezes inoperantes, ou mesmo contraproducentes; as tipologias, categorizações e normativos político-institucionais afiguram-se desadequados ou anacrónicos, apelando a uma reflexão profunda sobre a necessidade de processos renovados de legitimação e de refundação profissional. As competências de adaptação e de métissage, quer dos destinatários das ajudas, quer do próprio 
trabalhador social afirmam-se, assim, perante o domínio inequívoco da contingência e da particularidade.

A valorização atual do aproveitamento e potencialização de recursos (pessoais e territoriais) decorre, na nossa ótica, de três fatores articulados: 1. a diminuição dos recursos públicos, sobretudo de cariz financeiro; 2 . a avaliação dos mecanismos de dependência e a ineficácia das respostas sociopolíticas indemnizatórias; 3. a afirmação da autonomia e da responsabilidade associadas ao respeito ético pela dignidade e pela capacidade de escolha dos sujeitos da vida que pretendem viver.

Isto pressupõe, no entanto, que ao reconhecimento da capacidade de escolha, extremamente relevante no respeito pela dignidade e autodeterminação das pessoas apoiadas, se associe a criação de possibilidades de concretizar essa escolha, o que passa necessariamente pelo investimento, público e privado, em estruturas de oportunidades equitativamente disponíveis no tecido socioeconómico. Particularmente neste âmbito adquire relevância o papel de "magistratura social" (Rosanvallon, 1995) a assumir hoje pelos interventores sociais. A concretização de tal "magistratura" pressupõe a capacidade de avaliar o individual no coletivo e o coletivo no individual. Por outras palavras, o reconhecimento da importância da narrativa pessoal na órbita da ação pública evidencia-se a partir do momento em que dos dramas individuais se destacam elementos que permitem identificar e compreender as causas sociais, colocando em destaque condições de vida e falhas das políticas públicas, projetando elementos individuais num universo coletivo e permitindo, por esta via, conjurar o julgamento direcionado exclusivamente para o sujeito excluído. Só desse modo a narrativa privada se pode constituir como um exemplar singular de uma experiência coletiva, evitando uma espécie de psicologização das desigualdades sociais, analisadas sob o ângulo das experiências singulares de desprezo social (Ion, Laval \& Ravon, 2007).

Em acréscimo cabe, nesta ótica, ao interventor social proceder à partilha de responsabilidades e funções entre os vários agentes sociais e assumir, ao mesmo tempo, um papel na construção de espaços de negociação que permitam definir os pressupostos, as condicionantes e as exigências de tal partilha, bem como o debate em torno das prioridades, das fronteiras da solidariedade, 
dos limiares da intervenção pública e privada, da garantia de equidade e qualidade de vida, do significado do trabalho e da integração.

Neste contexto de reajustamento das políticas sociais e da intervenção, o apoio aos indivíduos em dificuldades já não tem por base de legitimação a referência prioritária à cidadania social, ao bem comum ou a um qualquer tipo de categorização político-administrativa, mas antes o seu reconhecimento como pessoa' ${ }^{9}$, com as suas potencialidades e fragilidades. A referência atual prioritária à noção de Pessoa, em detrimento de utente, cidadão ou beneficiário, coloca o acento já não na identidade dos indivíduos como detentores de direitos ou produtores-consumidores, mas antes sobre a singularidade de cada indivíduo e sobre a sua capacidade e necessidade de inscrição social e dialógica no mundo (Ion, Laval \& Ravon, 2007).

Os trabalhadores sociais são, deste modo, confrontados com uma retórica paradoxal que sublinha, por um lado, a necessidade de desenvolver estratégias potenciadoras da inscrição social dos sujeitos, pelo aproveitamento das suas capacidades e experiências em prol da autonomia e, por outro, a exigência de assegurar uma presença constante no percurso de inclusão social dos mesmos, de modo a evitar as desligações sociais e económicas, e desse modo, minimizar os riscos de "morte social".

\subsection{As "figuras" do acompanhamento social atual}

A relação de ajuda, um eixo básico da profissionalidade e da ética da intervenção social (Autès, 1999; Soulet, 1997), coloca-se, neste contexto, em bases renovadas. O contato profissional singularizado, o "estar ao lado", tende a constituir-se como a via possível para a construção de novas ligações sociais e o mecanismo privilegiado para contenção da invisibilidade (Albuquerque, 2010), para colocar os excluídos sob a "luz do espaço público, encontrar-lhes

9 A referência atual prioritária à noção de Pessoa, em detrimento de utente, cidadão, beneficiário ou sujeito, coloca o acento já não na identidade dos indivíduos como detentores de direitos ou produtores-consumidores, mas antes sobre a singularidade de cada indivíduo e sobre a sua capacidade e necessidade de inscrição social e dialógica no mundo (Ion, Laval \& Ravon, 2007). 
uma identidade, ou fornecer-lhes uma, dar-lhes uma escala de mobilidade que os inscreva numa vontade de bem-estar social" (Laé, 1996, p. 25). Trata-se de assegurar uma espécie de "acompanhamento de religação".

Esta noção de acompanhamento social é utilizada a partir da década de 1980 sobretudo pelas associações de luta contra a exclusão como uma démarche de reinserção social e de reconstituição do elo social. "Desde então, este termo não deixa de adquirir importância a ponto de por vezes ser considerado como substitutivo da metodologia de intervenção da ajuda individualizada, tornada ajuda à pessoa" (Bouquet \& Garcette, 1999, p. 72).

Nesta perspetiva, o trabalho de "subjetivação" assegurado pelos interventores sociais concretiza-se sobretudo por três vias (Pattaroni, 2007): a singularização ou a personalização no domínio das interações; a responsabilização no domínio da abordagem contratual; a mobilização, no domínio da construção motivacional e das competências.

Estas três vias constituem-se como a base comum de práticas diferenciadas agregadas sob o conceito atual de acompanhamento social. Podemos identificar, nesta ótica, sobretudo duas lógicas, uma associada à ativação e inserção, outra associada à contenção do sofrimento:

\section{A) Acompanhamento social associado à ativação e inserção dos sujeitos}

A ativação, como pressuposto basilar de uma nova geração de políticas sociais, posiciona os interventores sociais como gestores de percursos de inserção /desinserção do mercado de trabalho de populações muito diferenciadas, quer em termos de potencialidades e trajetórias de vida, quer em termos de conceções de participação social e expetativas face ao futuro. A orientação ativacional alicerça-se sobre uma axiomática dupla: em primeiro lugar, o reconhecimento do indivíduo não como assistido mas como cidadão ativo, com direito à utilidade social e à vivência em sociedade (Castel, 1995); em segundo lugar, a corresponsabilização, quer do cidadão beneficiário, quer da sociedade, na efetivação de um percurso de participação societal plena (Roche, 1992).

Tais pressupostos traduzem-se, entre outras implicações, na transmutação de dispositivos abstratos em medidas concretas e adaptadas ao perfil dos destinatários (singularização). Deste modo, a avaliação das características, 
experiências, competências e motivações de cada cidadão torna-se um eixo central da intervenção.

As práticas e procedimentos de ação tornam-se pois "adhocráticos” (Franssen, 2003), contratualizados, singularizados. A lógica do projeto pessoal e dos portefólios de competências, hoje tão presentes na intervenção social, ilustram bem estas orientações. Deste modo, o beneficiário torna-se coprodutor da ajuda, logo, partilha de forma inequívoca a responsabilidade pela assunção dos resultados visados e contratualizados. Afirma-se a autodeterminação como pressuposto de autonomização. O interventor social constitui-se, neste contexto, como o "incentivador" das possibilidades de agir e como adjuvante no percurso de (re)descoberta, de validação do adquirido e/ou de desenvolvimento das capacidades e competências dos sujeitos para essa ação. O acompanhamento social combina, neste caso, elementos retrospetivos e prospetivos. Multiplicam-se, deste modo, as avaliações das situações de vida e dos percursos profissionais, captando e valorizando o investimento subjetivo e mediatizando a construção de elos entre o indivíduo, intimado a viver e a provar as suas capacidades, e a sociedade. A implicação, a vontade manifestada pelo sujeito em dificuldades, constitui-se pois, numa perspetiva de ativação, como a base de um certo julgamento técnico, e mesmo coletivo, sobre o valor e a capacidade de cada pessoa na resolução dos seus próprios problemas.

Em paralelo, o interventor social, por via de um trabalho de mediação, estabelece as condições contratuais para a (re)entrada dos indivíduos na sociedade e, em particular, no mundo laboral. O "saber-dizer", as competências negociais, argumentativas e motivacionais adquirem nesta ótica a maior relevância.

Os interventores sociais confrontam-se, no entanto, neste trabalho de tecelagem de novos elos, com três contradições constitutivas, por um lado, a necessidade de simultaneamente referenciar o sujeito à sua história (a ancoragem no adquirido) e de ajudá-lo a libertar-se dela (ou do que tem de menos positivo) no sentido de se autonomizar e de construir novos caminhos; por outro, a diferenciação entre a retórica e a prática da inserção. Se teoricamente se preconiza a adaptação das medidas aos cidadãos, numa ótica de singularização, na verdade, são os cidadãos que devem adaptar-se às medidas e às expectativas sociais que elas encerram. De facto a exigência que se coloca ao indivíduo de demonstração de uma vontade de inserção, cuja concretização 
em grande medida não domina, consagra-o paradoxalmente como princípio e fim de si mesmo, como alguém reduzido ao momento ou ao problema que vivencia e que, para o melhor e para o pior, é julgado pelos sucessos ou pelas falhas do seu percurso. Por fim, a assimetria de poderes que está inerente à relação com o beneficiário. Ainda que partilhando a produção da ajuda com o beneficiário não deixa de caber ao interventor social a determinação dos pressupostos dessa ajuda e a avaliação dos produtos e percursos construídos.

A assunção da dimensão política da prática afigura-se-nos, neste âmbito, como particularmente importante. A ponderação crítica e reflexiva dos processos de ação e dos dispositivos políticos, e respetivas contradições ou insuficiências, bem como a clarificação dos critérios (associando pressupostos de singularização a pressupostos de uniformidade e generalidade) subjacentes ao acompanhamento, à contratualização e à avaliação constituem-se como elementos cruciais numa intervenção social capaz de anular suspeitas de discricionariedade e de acriticismo na aplicação das medidas.

B) Acompanhamento social associado à contenção do sofrimento:

O acompanhamento social associado à contenção do sofrimento pessoal e social evidencia-se hoje com particular relevância perante a fragmentação dos pressupostos de integração tradicionais e a constatação da impossibilidade, ou dificuldade extrema, de participar, social e economicamente, para grupos cada vez mais extensos e heterógeneos de "normais inúteis" (Castel, 1995).

Nesta perspetiva, instaura-se uma forma de intervenção a que Castel e Laé (1992) chamaram "tratamento oblíquo dos indivíduos". A alteração da gramática social da existência dos excluídos atuais pressupõe, como já salientámos, fornecer-lhes as oportunidades de expressão de si, possibilitando a sua participação no debate público e impulsionando ações e acontecimentos de retecelagem dos laços sociais. De facto, os excluídos são fagocitados por uma série de condicionantes que os impedem de se reconhecerem a si mesmos e na partilha com os outros: a luta incessante e desgastante pela sobrevivência quotidiana, a reconfirmação constante e interiorizada da sua incapacidade de vencer, o medo de verbalizar a sua condição, a sua existência sem presente e sem futuro e a mensagem, politico-socialmente transmitida e interiormente sedimentada, de uma fatalidade na situação que vivenciam, constituem-se 
como as bases de um sofrimento social profundo e disseminado. A estes fatores associa-se, na maioria das vezes, uma cultura institucional e normativa no quadro da qual aqueles a quem é exigido que façam prova do seu envolvimento, da sua capacidade de colaboração com a sociedade, raramente participam na definição das regras a que têm de conformar-se. Como salienta Michel Autès (1992) se os excluídos participassem da história com toda a certeza mudariam o argumento e deixariam de ser apenas figurantes, ou sombras sem consistência projetadas no "ecrã social".

O elemento da escuta de "males indizíveis" (Fassin, 2004) e da relação de ajuda como espaço de ancoragem com o real tornam-se, neste caso, os eixos basilares de um acompanhamento, designado por Ravon (2005) de "clínica do elo desfeito".

Consoante os graus de desagregação desse elo as práticas de acompanhamento assumem a forma de orientação, de reconstituição de referenciais do indivíduo consigo mesmo e com os outros num mundo com limites, mas também com oportunidades plurais e contraditórias. Deste modo, a subjetivação da prática assume a forma de personalização, de reconstituição do sujeito como pessoa moral, ponto prévio à sua afirmação e reconstrução como ator social e político. O longo prazo assume neste âmbito toda a relevância, colocando como grandes desafios da intervenção social a comprovação da eficácia da ajuda e a neutralização de suspeitas de psicologização da prática.

Com efeito, o acompanhamento social pode tornar-se uma mera recondução e revalidação do provisório; uma tentativa de subir uma escada rolante pelo lado que desce. No limite, pode mesmo constituir-se como um processo de centração na impossibilidade de assegurar um enquadramento social e económico adequado, e relativamente perene, para um número cada vez maior de sujeitos vulnerabilizados ou excluídos; uma espécie de instância de interposição entre os indivíduos e a sociedade; um "provisório permanente" (Rocher, 2004), que não deixa de configurar a possibilidade de uma reorientação profissional de um pressuposto de justiça social para um pressuposto de "justiça individual".

Neste sentido, a reflexão crítica e a superação de abordagens excessiva e/ ou exclusivamente centradas na temporalidade presente, e em leituras individualizantes dos problemas sociais contemporâneos, parece-nos essencial 
para a fundação de uma intervenção política e social que não seja mera reconfirmação da impossibilidade de pensar e agir para além de um quadro temporal e espacial restrito, de cumplicidade com o presentismo e, como tal, potencialmente invalidante.

\section{Conclusão}

A publicização da vida pública e privada dos sujeitos torna-se efetivamente um elemento fundamental de um novo paradigma político-social, valorizando o sentido de si e do conteúdo ético da vida, a construção singular de existências, a individualidade construída. No entanto, embora o reconhecimento dos sujeitos como seres capazes de reconstituir a sua própria vida e integração, pelo uso adequado das suas capacidades e competências (pré existentes ou reconstruídas), seja algo de intrinsecamente positivo, a centração exclusiva das intervenções sociopolíticas em pressupostos de subjetivação pode potenciar os fenómenos excludentes que pretenderia neutralizar, porquanto ao valorizar primordialmente, para o melhor e para o pior, o percurso de vida dos indivíduos, enfatiza mais a relação destes com a sua própria história do que a relação que estabelecem, ou podem estabelecer, com os outros membros sociais (Fitoussi \& Rosanvallon, 1997).

Individual e coletivo têm necessariamente de se constituir, sob este prisma, como duas faces de uma mesma moeda que só dessa forma adquire sentido. Uma intervenção social centrada exclusivamente numa perspetiva individual e familiar configura-se como potencialmente paliativa, moralizante excludente, já que pode contribuir para ocultar as raízes sociais (logo partilhadas) das desigualdades e das situações problema; uma intervenção centrada exclusivamente numa dimensão coletiva configura-se como potencialmente abstrata, formal e (também) excludente, já que pode contribuir para o esquecimento das vivências, das necessidades, das expectativas e do sofrimento concreto dos sujeitos, bem como das respetivas possibilidades e potencialidades de autossuperação.

Nesta ótica, os trabalhadores sociais, como agentes de mediação e conexão entre níveis de ação, discursos e temporalidades distintas podem, 
de facto, constituir-se como agentes de recriação do futuro, assumindo um projeto de sociedade que ultrapasse a imediatez e as situações individuais, sem contudo as esquecer ou ocultar. A determinação e justificação da justa medida, a consideração dos contextos de referência do outro, a ponderação da "écologie relationnelle des personnes aidées" (Ion, Laval \& Ravon, 2007, p. 166) e a reinscrição plausível das provas de injustiça, e das suas componentes singular e geral em espaços partilhados de argumentação e negociação, consagra o potencial renovado da intervenção social em sociedades polifónicas e sincréticas. Deste modo o grande trunfo profissional dos trabalhadores sociais consiste na utilização e aperfeiçoamento de competências de mediação entre espaços, existências, discursos, projetos e temporalidades (Albuquerque, 2010).

Desta forma, as competências dos interventores sociais atualmente mais relevantes não se associam tanto à qualificação técnica estrita, mas antes à capacidade para se posicionar adequadamente nos contextos, para visibilizar em espaços e com públicos diferenciados o que é feito e porquê, para identificar e saber ultrapassar o prescrito e para perspetivar e saber utilizar os diferentes parâmetros, limites e margens de autonomia propiciadas pelos referenciais sociopolíticos coexistentes na atualidade (Cauquil, 1994).

Perante os desafios atuais os interventores sociais devem pois constituir-se como "tradutores" que descodificam e recodificam fragmentos de saber e de acontecimentos. Profissionais que sabem aproveitar e consubstanciam as inúmeras ocasiões para dar sentido ao social, para nomear a sua diversidade, as suas plurirreferencialidades e racionalizações e para considerar, como afirma Jean Lavoue (1986), nas dimensões mais enriquecedoras do trabalho social - a relação, a proximidade, a troca, a conexão, a criatividade - o social em si com as suas ambiguidades, limites e potencialidades. Para tal a superação dos riscos de psicologização da prática e de individualização das desigualdades sociais pressupõe, por parte dos interventores sociais, um esforço de tradução e de religação pública dos sujeitos e dos problemas vivenciados, ou seja, uma dialética entre o individual e o coletivo, entre o particular e o geral, pela valorização da pessoa, do seu registo de cidadania e de dignidade, e da construção de sinergias com outros agentes sociais, políticos e económicos. 


\section{Bibliografia}

Albuquerque, C. (2010). Singularização da Ação Pública e Acompanhamento Social. Direito $e$ Cidadania "Politica Social e Cidadania", XI (30), nº especial, 67-85.

Arendt, H. (1987). A condição bumana. Rio de Janeiro: Editora Forense-Universitária Lda.

Astier, I. (1995). "Du Récit privé au récit civil: la construction d'une nouvelle dignité?", Lien Social et Politiques - RIAC, 34, 121-130.

Autès, M. (1992). Travail Social et Pauvreté. Paris: Syros Alternatives.

Autès, M. (1999). Les Paradoxes du Travail Social. Paris: Dunod.

Bal, M. B. de (1984). Société éclatée et nouveau travail social. La Revue Française de Service Social, 141/142, 43-57.

Beck, U. (1992). The Risk Society: Towards a new modernity. London: Sage.

Begaud, C. (1983). Réflexions sur l'éthique professionnelle. La Revue Française de Service Social, 136, 27-35.

Boulte, P. (1995). Individus en Friche. Paris: Desclée de Brouwer.

Bouquet, B. \& Garcette, C. (1999). Assistante Sociale aujourd'bui. Paris: Éditions Maloine.

Cantelli, F. \& Genard, J.-L. (2007). Jalons pour une sociologie politique de la subjectivité. In F.Cantelli \& J.-L.Genard (coords.), Droit et Société "Action Publique et Subjectivité». Paris: Réseau Européen Droit et Société e Maison des Sciences de l'Homme, 13-40.

Castel, R. \& Laé, J.F. (Org.) (1992). Le Revenu Minimum d'Insertion: Une Dette Sociale. Paris: L'Harmattan.

Castel, R. (1995). Les métamorphoses de la question sociale. Une chronique du salariat. Paris: Librairie Arthème Fayard.

Cauquil, G. (1994). Des Compétences pour décider. Informations Sociales «Nouvelles Missions, nouvelles formations", 38, 50-59.

Donzelot, J. \& Estèbe, Ph. (1994). L'État Animateur. Essai sur la politique de la ville. Paris: Édtions Esprit.

Elias, N. (1973). La Civilisation des Mours. Paris: Calmant-Lévy.

Fassin, D. (2004). Des Maux Indicibles. Sociologie des lieux d'écoute. Paris: Éditions la Découverte.

Fitoussi, J.-P. \& Rosanvallon, P. (1997). A nova era das desigualdades. Oeiras: Celta Editora.

Franssen, A. (2003). Le Sujet au coeur de la nouvelle question sociale. Revue Nouvelle, 1, 10-51.

Foucault, M. (1966). Les Mots et les Choses. Paris: Gallimard.

Gauchet, M. (1985). Le Désenchantement du Monde. Une histoire politique de la religion. Paris: Gallimard.

Genard, J.-L. (2007). Capacités ou capacitation: une nouvelle orientation des politiques publiques? In F. Cantelli \& J.L. Genard (coords.), Droit et Société "Action Publique et Subjectivité». Paris: Réseau Européen Droit et Société e Maison des Sciences de l'Homme, 41-64.

Giddens, A. (1994). Beyond Left and Right. The future of radical politics. Cambridge: Polity Press.

Ion, J., Laval, Ch. \& Ravon, B. (2007). Politiques de l'individu et psychologies d'intervention: transformations des cadres d'action dans le travail social. In F. Cantelli \& J.L Genard (coords.), Droit et Société "Action Publique et Subjectivité». Paris: Réseau Européen Droit et Société e Maison des Sciences de l'Homme, 157-168. 
Ion, J. (1998). Le Travail Social au singulier. Paris: Dunod.

Kouchner, B. (Org.) (1989). Les Nouvelles Solidarités. Paris: Presses Universitaires de France.

Laé, J.-F. (1996). L'Instance de la Plainte. Paris: Descartes.

Lavoue, J. (1986). Du "sens" des pratiques d'intervention et de changement chez les travailleurs sociaux. Cabiers de la Recherche sur le Travail Social "Les Discours du Social II", 11.

Le Strat, P. N. (1996). L'Implication. Une nouvelle base de l'intervention sociale. Paris: L'Harmattan.

Maffesoli, M. (1988). Les Temps des Tribus. Le déclin de l'individualism dans les sociétés de masse. s.1.: Librairie des Méridiens, Klinksieck et Cie.

Pattaroni, L. (2007). Le Sujet en l'Individu. La promesse d'autonomie du travail social au risque d'une colonisation par le proche. In F. Cantelli \& J.L. Genard (coords.), Droit et Société "Action Publique et Subjectivité". Paris: Réseau Européen Droit et Société e Maison des Sciences de l'Homme, 203-218.

Rancière, J. (1995). On the shores of politics. London: Verso.

Ravon, B. (2005). Vers une clinique du lien défait? In J. Ion (Ed.), Le Travail Social en Débat(s). Paris: La Découverte, 86-103.

Roche, M. (1992). Rethinking citizenship: Welfare, ideology and change in modern society. Cambridge: Polity Press.

Rocher, G. (2004). Le "polythéisme" des modes d'explication du social. In Colloque de l'AISLF, Québec (text policopié, résumé de la communication).

Rosanvallon, P. (1995). La Nouvelle Question Sociale. Repenser l'État-Providence. Paris: Seuil.

Soulet, M.-H. (1997). Petit Prècis de grammaire indigène du travail social. Règles, principes et paradoxes de l'intervention sociale au quotidien. Fribourg: Éditions Universitaires Fribourg Suisse.

Soulet, M.-H. (2007). L'Individualisation des politiques sociales: une réponse à l'exclusion durable? In F. Cantelli \& J.L Genard (coords.), Droit et Société "Action Publique et Subjectivité». Paris: Réseau Européen Droit et Société e Maison des Sciences de l'Homme, 169-179. 
(Página deixada propositadamente em branco) 
(Página deixada propositadamente em branco) 